\title{
Comparable Prognostic Value of Vasodilator Response to Acetylcholine in Brachial and Coronary Arteries for Predicting Long-Term Cardiovascular Events in Suspected Coronary Artery Disease
}

\author{
Bonpei Takase, MD; Akira Hamabe, MD; Kimio Satomura, MD; Takasi Akima, MD; \\ Akimi Uehata, MD; Takemi Matsui, PhD; Fumitaka Ohsuzu, MD; \\ Masayuki Ishihara, PhD; Akira Kurita, MD
}

\begin{abstract}
Background Vasodilator response to acetylcholine ( $\mathrm{ACh}$ ) (ie, endothelium-dependent dilation) is impaired in the peripheral and coronary circulation of patients with coronary risk factors and coronary artery disease (CAD). There is a close relationship of vasodilator response to ACh in both the coronary artery (CA) and the brachial artery (BA), but the comparative prognostic importance of these responses has not been fully investigated in relatively low-risk suspected CAD.

Methods and Results The flow responses of both the CA and BA were measured in 70 patients with suspected CAD, excluding patients with triple-vessel disease and known peripheral or cerebrovascular disorders. A Doppler guidewire was placed into a major branch of the CA and a proximal portion of the left BA. ACh was infused at $10^{-8}, 10^{-7}$ and $10^{-6} \mathrm{~mol} / \mathrm{L}$ for $3 \mathrm{~min}$ into the CA and at $7.5,15$, and $30 \mu \mathrm{g} / \mathrm{min}$ for $5 \mathrm{~min}$ into BA. The flow response was obtained by multiplying the average peak velocity by the cross-sectional area from quantitative angiography. Vasodilator response to $\mathrm{ACh}$ was assessed by the ratio of ACh-induced flow/baseline flow, expressed as coronary blood flow index (CBFI) or brachial blood flow index (BBFI). There were $39 \mathrm{CAD}$ patients $(61 \pm 8$ years old) and 31 normal coronary patients (NL, $58 \pm 11$ years old) who were followed up for $53 \pm 17$ months. Eleven patients had coronary events (CE) during this period: 1 case of nonfatal myocardial infarction and 10 cases of unstable angina. A strong correlation between CBFI and BBFI was observed at middle- and high-doses of ACh $\left(\mathrm{r}=0.72, \mathrm{p}<0.0001,15 \mu \mathrm{g} / \mathrm{min}\right.$ vs $10^{-7} \mathrm{~mol} / \mathrm{L} ; \mathrm{r}=0.76, \mathrm{p}<0.0001,30 \mu \mathrm{g} / \mathrm{min}$ vs $\left.10^{-6} \mathrm{~mol} / \mathrm{L}\right)$. Kaplan-Meier analysis, using the best cut-off values obtained from receiver-operating characteristic curves for $\mathrm{CE}$, revealed that both CBFI and CAFI were significant predictors for CE.

Conclusions The BA vasodilator response to optimal ACh dosage can be used as a surrogate prognostic predictor for coronary endothelial function tests in patients with suspected CAD. (Circ J 2006; 70: 49-56)
\end{abstract}

Key Words: Doppler flow; Endothelial function; Myocardial infarction; Unstable angina

厂 ipid abnormalities, hypertension, diabetes, smoking, and obesity are traditional coronary risk factors that cause endothelial dysfunction, inflammation, and altered biological pathways, ${ }^{1-4}$ which are well-recognized final common pathways for developing coronary artery (CA) atherosclerosis and are associated with an adverse outcome. Among several endothelial function tests, the vasodilator response to acetylcholine $(\mathrm{ACh})$ (ie, endothelium-dependent dilation) is widely used as a clinical modality and has been proved to be impaired in the peripheral and coronary circulation of patients with known coronary risk factors and/or manifest coronary artery disease (CAD) ${ }^{5,6}$ Recently, the prognostic value of endothelial vasomotor testing has been studied in either the CA or a peripheral artery of humans and it has been revealed that

(Received September 12, 2005; revised manuscript received October 24, 2005; accepted November 1, 2005)

National Defense Medical College Research Institute, Division of Biomedical Engineering and Internal Medicine-1, Saitama, Japan. Mailing address: Bonpei Takase, MD, FACC, FAHA, National Defense Medical College Research Institute, Division of Biomedical Engineering, 3-2 Namiki, Tokorozawa, Saitama 359-8513, Japan. E-mail: bonpeit@ndmc.ac.jp or dui1577@db3.so-net.ne.jp the endothelial function test has a significant prognostic advantage 7,8

Most studies have involved intermediate- to high-risk groups, such as those with serious $\mathrm{CAD}, 10$ peripheral vascular disease complications, ${ }^{1-13}$ or chronic renal disorders; ${ }^{14}$ few studies have used the endothelial function test in populations without manifest CAD or with coronary risk factors without clinically apparent disease ${ }^{15-17}$ In addition, to date the comparative prognostic value of coronary and peripheral vascular endothelial function tests has not been fully investigated.

In the present study, we simultaneously performed endothelial function tests in both the coronary and brachial arteries in patients with suspected CAD without high-risk complications. Therefore, the purpose of this study was to investigate whether or not the vasodilator response to $\mathrm{ACh}$ has a comparative prognostic significance in low- to moderate-risk populations.

\section{Methods}

\section{Study Population}

The study population comprised 77 consecutive patients 
who were referred to the Division of Cardiology in the National Defense Medical College with suspected CAD and who agreed to undergo coronary angiography following both $\mathrm{CA}$ and brachial artery (BA) endothelial function studies after giving detailed informed consent regarding the possible complications of these procedures. Seven patients were excluded because their coronary angiography revealed either severe CAD $(n=2)$ or 3 -vessel disease $(n=5)$ and they were ineligible for the coronary endothelial function study. The remaining 70 patients were enrolled (age range, 35-77 years, mean \pm SD $60 \pm 10$ years; 47 men, 23 women. Coronary angiography revealed 39 patients with CAD, which included significant stenosis (defined as a luminal diameter stenosis $\geq 70 \%$ in the CA major branch: CAD group) and 31 patients with no major CA stenoses (small irregularity in CA or normal CA: NL group). Coronary angiography was interpreted by at least 3 independent cardiologists. Any medications, including antianginal agents, were discontinued for at least 5 half-lives prior to either CA or BA endothelial function study. All patients refrained from drinking alcohol or beverages containing caffeine and from smoking for at least $24 \mathrm{~h}$ before the study. Both studies were performed at the same time in the catheterization laboratory. The research protocol was approved by the institute's review board. Cardiac risk factors, comorbid conditions, and selected clinical characteristics in both groups are shown in Table 1. Age and body-mass index were almost identical in both groups, there were more males in the CAD group, and cigarette smoking, hypertension, diabetes mellitus, hyperlipidemia (hypercholesterolemia), family history of premature atherosclerosis, serum levels of total cholesterol, highdensity lipoprotein cholesterol, and fasting blood sugar were not significantly different between the 2 groups.

\section{Study Protocol}

CA Endothelial Function Study After routine diagnostic coronary angiography and left ventriculography, the CA endothelial function study was performed. Normal CA were selected (ie, left anterior descending, left circumflex $\mathrm{CA}$ or right $\mathrm{CA}$ ); for example, if a patient had significant right $\mathrm{CA}$ stenosis, either the left anterior descending or the left circumflex CA was used for the study. After an intravenous bolus of 5,000 units of heparin, a 7 French $(\mathrm{F})$ guiding catheter was positioned in the left main or right coronary ostium and then a 2.5F infusion catheter (FRACKER-18, Boston Scientific Inc, CA, USA) was advanced through the guide catheter over a 0.014-in Doppler guidewire (Cardiometrics, Mountain View, CA, USA) into the proximal portion of the targeted CA. After the position of the infusion catheter was confirmed byfluoroscopy, the guidewire was withdrawn and reinserted through a $7 \mathrm{~F}$ guiding catheter into the same position as the infusion catheter.

To measure the coronary blood flow response to ACh, the following 3 grades of concentration of ACh were continuously infused into the distal portion of the targeted CA through an infusion catheter according to the modifications previously reported5 Briefly, serial intracoronary infusions were performed: (1) control infusion of normal saline at the infusion rate of $1 \mathrm{ml} / \mathrm{min}$ for $3 \mathrm{~min}$, (2) serial 3-min infusions of ACh (Ovisot, Daiichi Inc, Tokyo, Japan) at doses of $0.15 \mu \mathrm{g}, 1.50 \mu \mathrm{g}$, and $15 \mu \mathrm{g}$ dissolved in $1 \mathrm{ml}$ normal saline at an infusion rate of $1 \mathrm{ml} / \mathrm{min}$, and achieving a final estimated intracoronary concentrations of $10^{-8}, 10^{-7}, 10^{-6} \mathrm{~mol} / \mathrm{L}$ (low-, middle-, and high-doses of ACh, respectively). During infusion, blood pressure, heart rate, and electrocardio- gram were all continuously monitored. The coronary flow velocity was also continuously recorded during the ACh infusion. We used the selected doses of ACh in the CA because a dose of ACh lower than $10^{-5} \mathrm{~mol} / \mathrm{L}$ is reported to act only on endothelium but not CA smooth muscle 18 In addition, continuous infusion of $\mathrm{ACh}$ was performed instead of bolus injection in order to maintain a relatively steady concentration of ACh in the each artery.

Quantitative coronary angiographic images were obtained at the end of the control infusion and each ACh infusion. In addition, $8 \mathrm{ml}$ of contrast agent (Ioversol, 74\%, Yamanouchi Inc, Tokyo, Japan) was injected for coronary angiography. For quantitative coronary angiography, technically suitable cineangiography frames were selected for computer analysis. Using a commercial software package (Kontron Elektronik, Cardio 500, Boston, MA, USA), containing a digitizing board, the diameters of the selected vessels were measured. For these measurements, an automated edge detection program was used to determine the densities and identify inflection points. Using this method, and making manual corrections if necessary, the segment diameter of the vessel of interest was measured along the length of the selected segment. Segments measuring $10 \mathrm{~mm}$ in length and 10 $15 \mathrm{~mm}$ distal from the infusion catheter were selected for analysis, based on the optimal region for performing quantitative coronary angiographic analysis.

The time-averaged (mean of 3 beats) peak velocity (average peak velocity, which is similar to the mean velocity over 1 cardiac cycle) was recorded immediately before coronary angiography for the vascular response study. The flow volume in the CA was calculated by multiplying the average peak velocity and the vessel cross-sectional area $\left(\pi \mathrm{r}^{2}\right)$ derived from quantitative coronary angiography using the formula: coronary blood flow $(\mathrm{ml} / \mathrm{min})=$ average peak velocity $(\mathrm{cm} / \mathrm{s}) / 2 \times \pi^{2} \times 0.15$, according to previous reports. ${ }^{19,20}$ The relative increase in the coronary blood flow for each ACh infusion was calculated as the maximal flow recorded at the end of each dose of ACh divided by the flow obtained under control infusion (coronary blood flow index). Quantitative coronary angiography analysis and the measurement of the average peak velocity were performed by 1 of the investigators (T.A.) who was unaware of any clinical data.

BA Endothelial Function Study The vasodilator response to ACh in the BA was assessed in the patients using serial catheterization of the left BA immediately after or before the $\mathrm{CA}$ endothelial function study was performed. A $6 \mathrm{~F}$ right Judkins-type guiding catheter was advanced into the proximal portion of the BA and a Doppler guidewire and the infusion catheter were inserted. The BA blood flow in response to graded concentrations of ACh was measured in the same way as in the CA endothelial function study. Serial infusions were performed according to a modification of a previously reported method:21 (1) control infusion of normal saline at the infusion rate of $1 \mathrm{ml} / \mathrm{min}$ for $5 \mathrm{~min}$, (2) serial 5-min infusions of ACh in doses of $7.5 \mu \mathrm{g}, 15.0 \mu \mathrm{g}$, and $30.0 \mu \mathrm{g}$ dissolved in $1 \mathrm{ml}$ normal saline at the infusion rate of $1 \mathrm{ml} / \mathrm{min}$ (low-, middle-, and high-doses of ACh, respectively). At the end of each infusion dose, $4 \mathrm{ml}$ of contrast agent (Ioversol, 74\%) diluted with $4 \mathrm{ml}$ normal saline were injected for brachial angiography. According to the same method as used in the CA endothelial function study, the brachial blood flow $(\mathrm{ml} / \mathrm{min})$ and brachial blood flow index were calculated.

All patients underwent either a $\mathrm{CA}$ or $\mathrm{BA}$ endothelial 
Table 1 Clinical Characteristics of the Study Population

\begin{tabular}{|c|c|c|}
\hline & $C A D$ group $(n=39)$ & $N L$ group $(n=31)$ \\
\hline Age, years & $61 \pm 8$ & $58 \pm 11$ \\
\hline Men & $32(82) *$ & $15(48)$ \\
\hline Body mass index, $\mathrm{kg} / \mathrm{m}^{2}$ & $23.0 \pm 3.2$ & $22.8 \pm 3.6$ \\
\hline Current smoker & $24(62)$ & $13(42)$ \\
\hline Hypertension & $25(61)$ & $17(55)$ \\
\hline Diabetes mellitus & $12(30)$ & $6(19)$ \\
\hline Hyperlipidemia & $21(54)$ & $16(52)$ \\
\hline Family history of coronary artery disease & $7(18)$ & $5(23)$ \\
\hline Total cholesterol $(\mathrm{mg} / \mathrm{dl})$ & $210 \pm 28$ & $208 \pm 34$ \\
\hline Triglyceride $(\mathrm{mg} / \mathrm{dl})$ & $149 \pm 65$ & $153 \pm 70$ \\
\hline HDL cholesterol $(\mathrm{mg} / \mathrm{dl})$ & $58 \pm 19$ & $55 \pm 17$ \\
\hline Fasting blood sugar $(\mathrm{mg} / \mathrm{dl})$ & $114 \pm 44$ & $122 \pm 60$ \\
\hline \multicolumn{3}{|l|}{ No. of diseased vessels } \\
\hline 0 & 0 & 31 \\
\hline 1 & $19(49)$ & 0 \\
\hline 2 & $20(51)$ & 0 \\
\hline Revascularization procedures at baseline therapy & $7(18)$ & 0 \\
\hline \multicolumn{3}{|l|}{ Coronary blood flow index } \\
\hline Low-dose infusion of $A C h$ & $1.07 \pm 0.20 *$ & $1.20 \pm 0.24$ \\
\hline Middle-dose infusion of ACh & $1.30 \pm 0.42 *$ & $1.78 \pm 0.66$ \\
\hline High-dose infusion of ACh & $1.59 \pm 0.74 *$ & $2.45 \pm 0.77$ \\
\hline \multicolumn{3}{|l|}{ Brachial blood flow index } \\
\hline Low-dose infusion of $A C h$ & $1.09 \pm 0.32 *$ & $1.51 \pm 0.42$ \\
\hline Middle-dose infusion of ACh & $1.32 \pm 0.36^{*}$ & $2.01 \pm 0.88$ \\
\hline High-dose infusion of ACh & $1.64 \pm 0.74 *$ & $2.61 \pm 1.11$ \\
\hline$A S A$ & $23(59)$ & $15(48)$ \\
\hline$\beta$-blockers & $9(23)$ & $7(23)$ \\
\hline Calcium antagonist & $30(77)$ & $16(52)$ \\
\hline Nitrates & $17(44)$ & $9(29)$ \\
\hline ACE inhibitors & $9(23)$ & $8(26)$ \\
\hline Statins & $9(23)$ & $7(23)$ \\
\hline
\end{tabular}

Data are mean $\pm S D$ and numbers in parenthesis express percentages.

CAD group, patients with coronary artery disease; NL group, patients with non-significant coronary artery stenosis; hypertension, blood pressure $\geq 160 / 95 \mathrm{mmHg}$; diabetes mellitus, fasting blood sugar $\geq 126 \mathrm{mg} / \mathrm{dl}$; hyperlipidemia, total cholesterol $\geq 230 \mathrm{mg} / \mathrm{dl}$; $H D L$, high density lipoprotein; ACh, acetylcholine; ASA, aspirin; ACE, angiotensin-converting enzyme. ${ }^{*} p<0.05 v s$ NL group.

function study in random order to avoid any interaction between the studies. Both studies were performed at approximately $15.00 \mathrm{~h}$ within $30 \mathrm{~min}$ intervals.

\section{Endpoint and Follow-up}

Clinical long-term follow-up was performed by reviewing the death certificates and hospital records, and telephone conversations with the local treating physician, the patient or the patient's relatives. During follow-up, the time to the occurrence of cardiac events (CE) was assessed. CE were defined as cardiac death, myocardial infarction (MI), or hospital readmission for unstable angina (UA). MI was defined as new ST elevations $(>0.1 \mathrm{mV})$ in 2 contiguous leads or an elevation of creatine kinase levels $>2$-fold the upper limit of normal. Because aspirin, $\beta$ blocking agents, angiotensin-converting enzyme inhibitors, and statins might affect either endothelial vasodilator function or disease progression, these medical therapies were documented during follow-up.

\section{Statistical Analysis}

All data are presented as the mean \pm SD at a $95 \%$ confidence interval $(\mathrm{CI})$ or frequency $(\%)$, unless otherwise stated. The baseline clinical characteristics of the groups were compared using the 2-tailed Student's t-test for continuous variables and the chi-square or Fisher exact test for noncontinuous variables, as appropriate. The ACh-induced blood flow response data in both the $\mathrm{CA}$ and $\mathrm{BA}$ were examined with ANOVA corrected by the Scheffe method
Table 2 Correlation Between the Coronary and Brachial Blood Flow Indices and the Coronary Blood Flow Index vs the Brachial Flow Index at Various Doses of Acetylcholine

\begin{tabular}{ccc}
\hline \hline Acetylcholine level & \multicolumn{2}{c}{ All patients $(n=70)$} \\
\hline Low-dose & $r=0.06$ & $N S$ \\
Middle-dose & $r=0.72$ & $p<0.001$ \\
High-dose & $r=0.76$ & $p<0.001$ \\
\hline
\end{tabular}

or Student's t-test. Correlations between the CA and BA were obtained by the Pearson's product-moment correlation. A receiver-operating characteristic (ROC) curve was used to acquire appropriate sensitivity and specificity for the diagnostic tests, and to identify the best threshold value for predictors of CE. Survival was illustrated with KaplanMeier curves, and outcomes were compared using the log-rank test. Multiple logistic regression analysis was performed to identify the independent variables for predicting CE. All of these statistical analyses were performed using SPSS version 11.0 (SPSS Japan Inc, Tokyo, Japan). Statistical significance was assumed if the null hypothesis was rejected at the $\mathrm{p}<0.05$ level.

\section{Results}

CA and BA Blood Flow Indices

Routine coronary angiography revealed 39 patients with significant CAD (CAD group) and 31 patients without 
a Coronary angiogram of left descending coronary artery

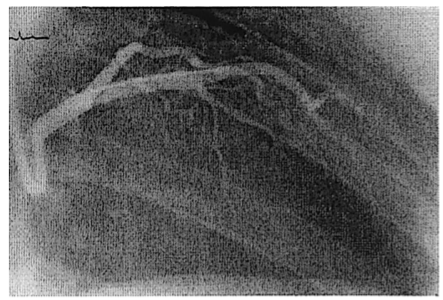

\section{d Brachial angiogram of left brachial artery}

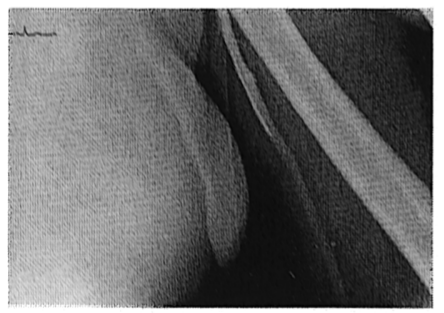

b Coronary blood flow velocity in control infusion

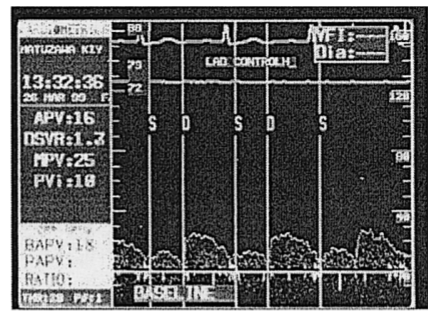

C Coronary blood flow velocity in middledose infusion of acetylcholine

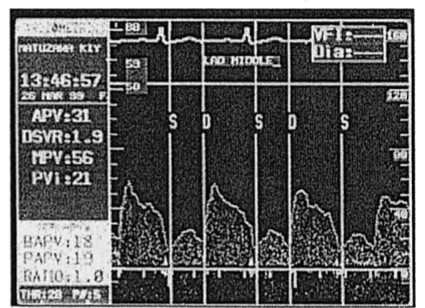

e Brachial blood flow velocity in control infusion

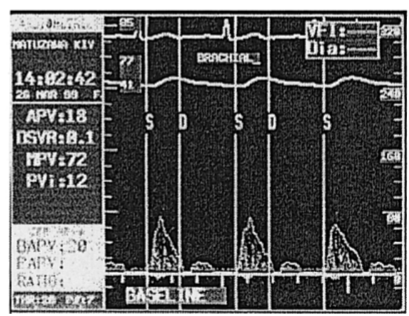

f Brachial blood flow velocity in middledose infusion of acetylcholine

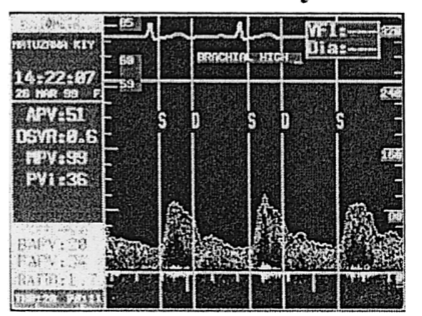

Fig 1. The typical real time tracing of coronary and brachial blood flow velocity and calculated blood flow indices in middle-dose infusion of acetylcholine (ACh) are illustrated in 57 years old man belongs to NL group (patients without coronary artery disease). (a) Coronary angiogram of left descending coronary artery. (b) Coronary blood flow velocity in control infusion; Average peak velocity $=16 \mathrm{~cm} / \mathrm{s}$, calculated coronary blood flow $=90 \mathrm{ml} / \mathrm{min}$. (c) Coronary blood flow velocity in middle-dose infusion of ACh; Average peak velocity $=31 \mathrm{~cm} / \mathrm{s}$, calculated coronary blood flow $=190 \mathrm{ml} / \mathrm{min}$, calculated coronary blood flow index was 2.11. (d) Brachial angiogram of left brachial artery. (e) Brachial blood flow velocity in control infusion; Average peak velocity $=18 \mathrm{~cm} / \mathrm{s}$, calculated brachial artery blood flow $=170 \mathrm{ml} / \mathrm{min}$. (f) Brachial blood flow velocity in middle-dose infusion of ACh; Average peak velocity $=51 \mathrm{~cm} / \mathrm{s}$, calculated brachial artery blood flow $=427 \mathrm{ml} / \mathrm{min}$, calculated brachial blood flow index was 2.51 .
CAD (NL group). Both the CA and BA blood flow indices in the low-, middle-, and high-dose infusions of ACh were significantly smaller in the CAD group than in the NL group (Table 1). The blood flow indices were significantly correlated with middle- and high-dose infusions of ACh, but not withlow-dose infusions of ACh (Table 2). A typical real time tracing of $\mathrm{CA}$ and $\mathrm{BA}$ blood flow velocity and calculated blood flow indices with middle-dose infusion of ACh is shown in Fig 1.

\section{Long-Term Follow-up and the CA and BA Blood Flow Indices}

The mean follow-up period was $53 \pm 17$ months and during this period, there were $11 \mathrm{CE}$ (Table 3 ): 1 case of MI and 10 of UA. Two NL group patients had frequent angina attacks at rest requiring readmission and they were labeled as UA; however, coronary angiography revealed no significant stenosis, and therefore vasospastic angina was diagnosed on the basis of subsequent ACh-provoked vasospasm. The remaining 8 patients with UA had CAD on baseline coronary angiography and 3 of them developed new coronary lesions in the vessel in which the CA endothelial function study was conducted, and 7 underwent revascularization procedures ( 3 coronary bypass surgeries, 4 percutaneous coronary interventions).

Patients without CE, when compared with those with $\mathrm{CE}$, showed significantly impaired CA and BA blood flow indices with middle-dose infusions of $\mathrm{ACh}$, and smaller coronary blood flow indices with high-dose infusions of ACh (Fig 2). Patients without CE tended to have smaller $\mathrm{BA}$ blood flow indices with high-dose infusions of $\mathrm{ACh}$ $(p=0.06)$. ROC curve analyses were performed to examine the sensitivity and the specificity of CA and BA blood flow indices with middle- and high-dose infusions of $\mathrm{ACh}$ for predicting $\mathrm{CE}$ (Fig 3). From the ROC curve analysis, the best cut-off values for each index were determined (CA 
Table 3 Patients With Cardiac Events During Follow-up

\begin{tabular}{ccccccc}
\hline \hline Case no. & Age (years) & Sex & CAD & Type of event & Revascularization procedure & Time to event (months) \\
\hline 12 & 69 & Male & $C A D$ & $U A$ & $P C I$ & 62 \\
17 & 69 & Female & $C A D$ & $U A$ & $C A B G$ & 54 \\
22 & 50 & Male & $C A D$ & $U A$ & $P C I$ & 40 \\
28 & 66 & Male & $C A D$ & $U A$ & $C A B G$ & 2 \\
31 & 68 & Female & $N L$ & $U A^{*}$ & Medical treatment & 34 \\
33 & 70 & Male & $C A D$ & $M I$ & Medical treatment & 24 \\
34 & 45 & Male & $C A D$ & $U A$ & $P C I$ & 48 \\
37 & 67 & Female & $C A D$ & $U A$ & $C A B G$ & 13 \\
46 & 61 & Male & $N L$ & $U A^{*}$ & Medical treatment & 38 \\
47 & 64 & Male & $C A D$ & $U A$ & PCI & 72 \\
59 & 68 & Male & $C A D$ & $U A$ & Medical treatment & 72
\end{tabular}

$C A D$, coronary artery disease; $P C I$, percutaneous coronary intervention; UA, unstable angina; $C A B G$, coronary bypass surgery; $N L$, no significant coronary artery disease.

*subsequently and newly diagnosed as vasospastic angina pectoris.

a

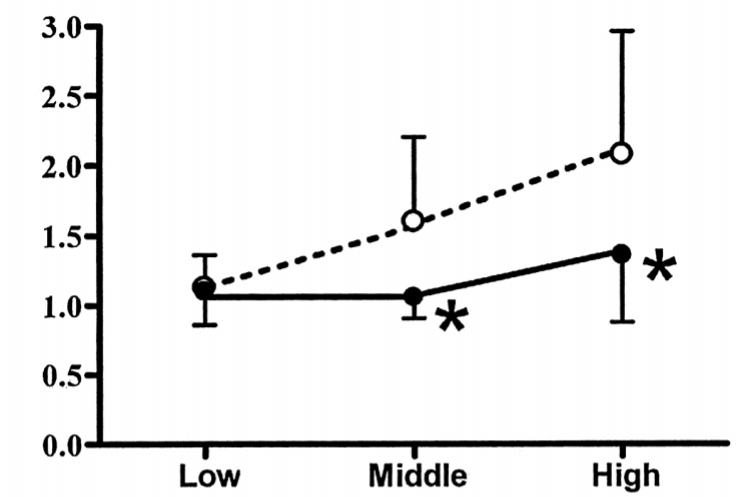

b

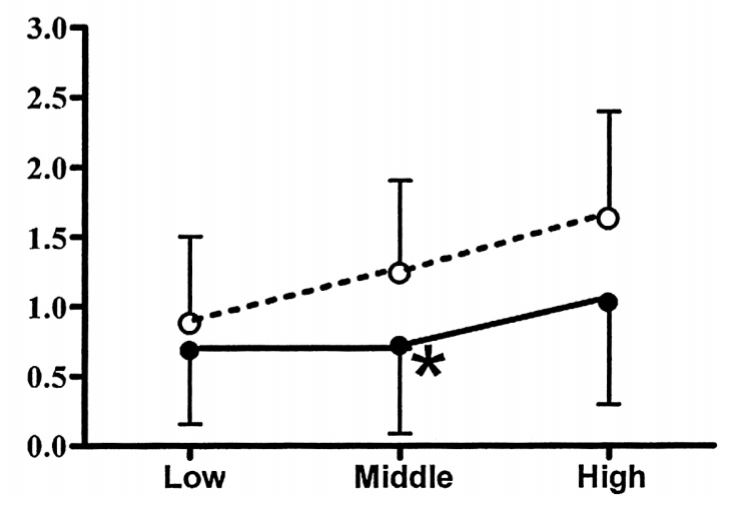

Fig 2. Changes in (a) the coronary and (b) the brachial blood flow indices using graded doses (low, middle, and high) of acetylcholine. Patients with (solid line) and without (dotted line) cardiac events, $\bullet$ cardiac event $(+)$; $\bigcirc$, cardiac event $(-)$. $* \mathrm{p}<0.05$ vs cardiac event $(-)$. Mean \pm SD.

blood flow index for middle- and high-dose infusions of $\mathrm{ACh},<1.17$ and $<1.31$, respectively; BA blood flow index for middle- and high-dose infusions of ACh, $<1.19$ and $<1.54$ respectively). Using these cut-off values, KaplanMeier CE free survival curves were constructed. As shown in Fig 4, patients with poor CA blood flow indices for middle- and high-dose infusions of $\mathrm{ACh}$ and poor BA blood flow indices for middle-dose infusions of ACh had significantly more $\mathrm{CE}$ than those without these poor
ROC curve for cardiac event

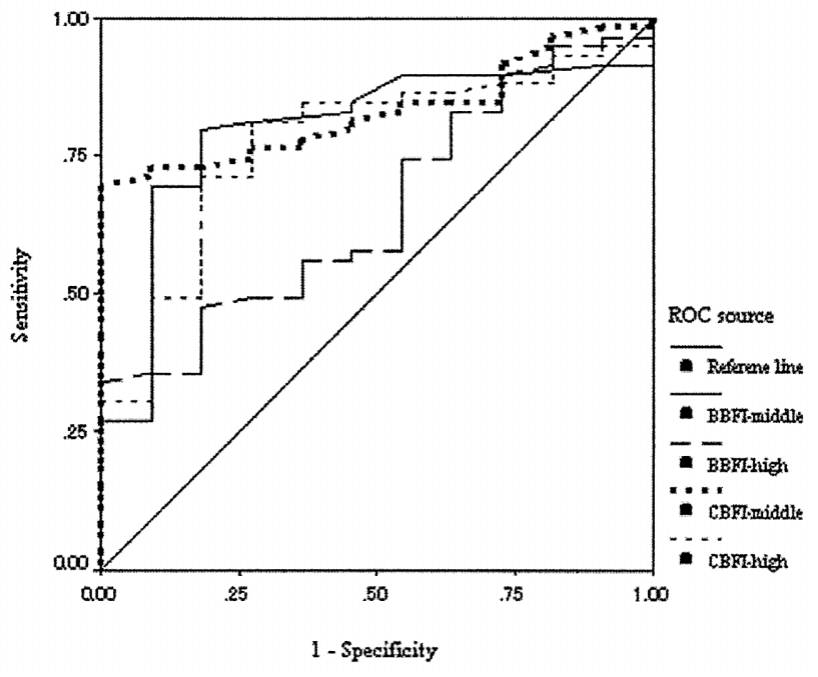

Fig 3. Receiver-operating characteristic curves for the sensitivity and the specificity of cardiac events. CBFI-middle, coronary blood flow index for middle-dose infusion of acetylcholine, cut-off value $<1.17$; CBFI-high, coronary blood flow index for high-dose infusion of acetylcholine, cut-off value $<1.31$; BBFI-middle, brachial blood flow index for middle-dose infusion of acetylcholine, cut-off value $<1.19$; BBFI-high, brachial blood flow index for high-dose infusion of acetylcholine, cut-off value $<1.54$. ROC, receiver-operating characteristic.

indices.

In order to compare the predictive value of $\mathrm{CA}$ and $\mathrm{BA}$ blood flow indices with conventional clinical variables, we performed multiple logistic regression analysis for all CE. Baseline clinical characteristics, such as coronary risk factors, the number of diseased vessels, baseline revascularization procedure, and left ventricular ejection fraction, were included as independent variables. In addition, the information on follow-up medication was included. As a result, the univariate predictors for $\mathrm{CE}$ were $\mathrm{CA}$ and $\mathrm{BA}$ blood flow indices for middle-dose infusions of ACh, CA blood flow index for high-dose infusions of $\mathrm{ACh}$, and the number of diseased vessels. However, both the CA and BA blood flow indices for middle-dose infusions of $\mathrm{ACh}$, as well as the CA blood flow index for high-dose infusions of $\mathrm{ACh}$, were the only multivariate predictors for $\mathrm{CE}$ (CA blood flow index for middle-dose infusions of $\mathrm{ACh}$, odds 
a

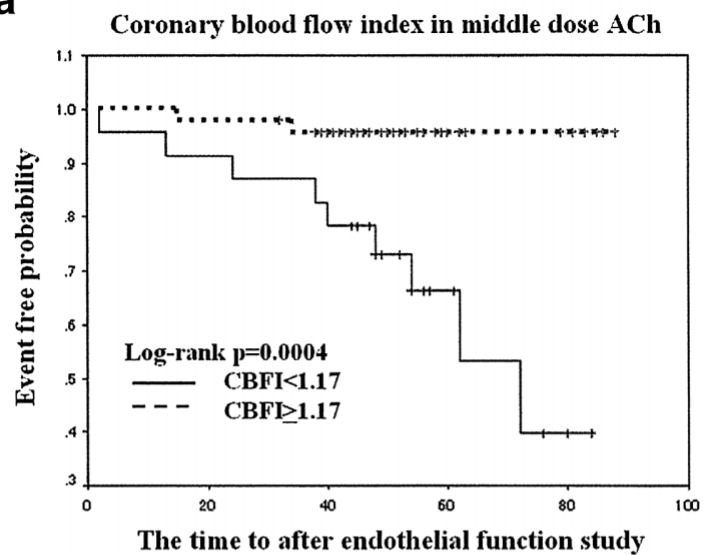

C

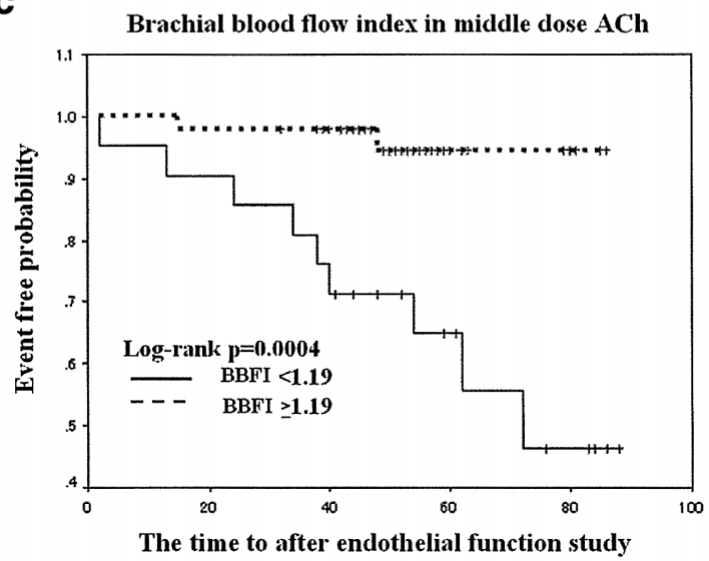

b

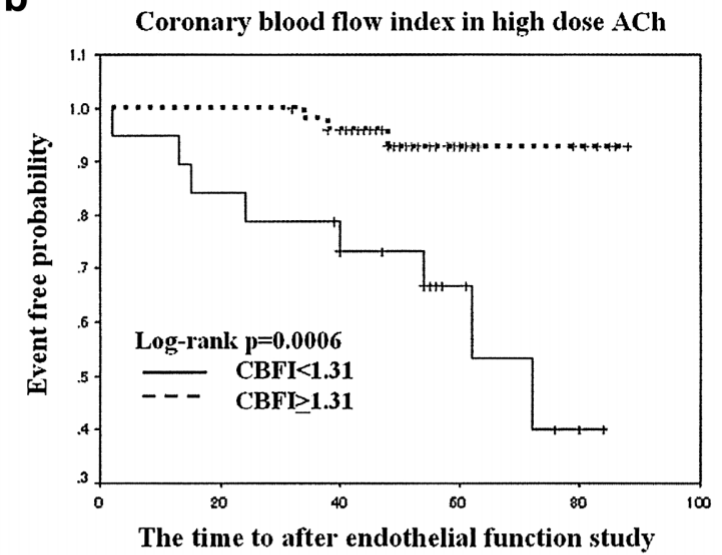

d

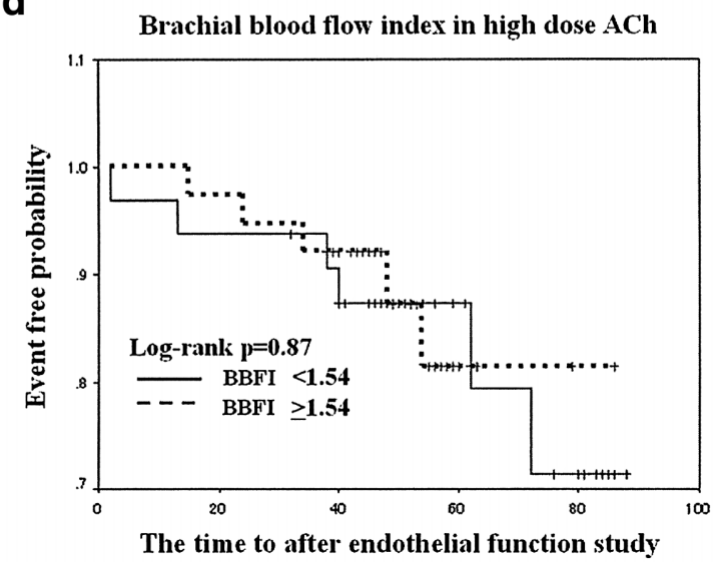

Fig 4. Kaplan-Meier curves showing cumulative proportion of patients without cardiac events during follow-up. Patients were divided into normal or poor endothelial function according to appropriate cut-off values obtained form receiver-operating characteristic curve. Coronary blood flow index with (a) middle-dose and (b) high-dose infusion of acetylcholine (ACh). Brachial blood flow index with (c) middle-dose and (d) high-dose infusion of ACh. CBFI, coronary blood flow index; BBFI, brachial blood flow index.

ratio $(\mathrm{OR})=19.6,95 \% \mathrm{CI} 1.1-340.8, \mathrm{p}<0.05$; BA blood flow index for middle-dose infusions of $\mathrm{ACh}, \mathrm{OR}=60.9,95 \% \mathrm{CI}$ 2.7-1368.7, $\mathrm{p}<0.01$; CA blood flow index for high-dose infusions of ACh, OR=25.3, 95\%CI 2.6-250.5, p<0.01).

\section{Discussion}

In this study we have demonstrated that the endothelial function test using the vasodilator response to $\mathrm{ACh}$ in the $\mathrm{CA}$ and BA arteries has comparative prognostic value in low to moderate risk patients with suspected CAD.

None of the study population had prior MI or any other complications such as peripheral atherosclerotic vascular disease, chronic renal disorders, or manifested cerebrovascular disorders. Cardiac catheterization revealed that more than one-third of the study population had no significant luminal stenosis in a major coronary branch and the left ventricular function was preserved in each patient. Multiple logistic regression analysis that included the number of diseased coronary vessels and left ventricular ejection fraction showed that $\mathrm{CA}$ and $\mathrm{BA}$ endothelial function indices were independent predictors for subsequent CE. Also, Kaplan-Meier analysis using the best cut-off values obtained from the ROC curves for CE, revealed that both CA and $\mathrm{BA}$ endothelial function indices (CA and BA blood flow indices) were significant predictors for $\mathrm{CE}$.
Previous reports showed that both CA and BA artery endothelial functions predict subsequent $\mathrm{CE}$ in patients with $\mathrm{CAD}{ }^{7,8}$ In those reports, CA vasoreactivity to $\mathrm{ACh}$ was reduced in patients who had $\mathrm{CE}$. BA endothelial function study using flow-mediated vasodilatation or ACh infusion combined with plethysmography reportedly predicted CE in patients with CAD or at high risk?,10,22 These findings were similar if either a flow-mediated vasodilatation or an ACh infusion study was used as the endothelial function test. Those reports agree with our finding that impaired CA and BA artery endothelial function can predict the development of $\mathrm{CE}$ in patients with significant CAD. However, 2 patients without significant $\mathrm{CAD}$, but with decreased $\mathrm{CA}$ and BA artery endothelial function, developed CE. In earlier studies, endothelial function tests could predict CE even in relatively low-risk patients, such as those without manifest CAD or with newly diagnosed hypertension! $15,16,23$ This also agrees with our findings. The only discordant point in our study is that the 2 patients in the NL group who had a CE developed vasospastic angina without significant stenosis. Even if the reported prognosis of vasospastic angina pectoris is plausible, sudden cardiac death can occur in patients with very active vasospasm? 24,25 In this respect, newly developed active vasospastic angina can be considered a CE classified as UA.

Recent studies reported that BA endothelial function 
tests using flow-mediated vasodilatation do not predict $\mathrm{CE} ;{ }^{14,26}$ however, those populations included relatively large numbers of high-risk cohorts such as patients with renal dysfunction on dialysis. In high-risk patients, in terms of complicated advanced atherosclerosis, abnormal conditions, as represented by organic lesions, might have a more important role in the development of catastrophic CE than functional abnormality such as endothelial function. Endothelial function tests might lose their predictive power in high-risk populations and are more sensitive for predicting $\mathrm{CE}$ in the low risk populations, as found in the present study. Generally, most patients in outpatient clinics are categorized as low risk and the present results on endothelial function in low-risk populations are meaningful for routine clinical practice.

ACh-induced vasodilatation might be more sensitive than flow-mediated vasodilatation for predicting CE. Flowmediated vasodilatation is less sensitive in detecting endothelial dysfunction under some conditions. In fact, although flow-mediated vasodilatation in the BA significantly correlates with the vasodilator response to $\mathrm{ACh}$ in the $\mathrm{CA}$, the correlation coefficient is weak? In the early stage of endothelial dysfunction, some patients have impaired AChinduced vasodilatation, but flow-mediated vasodilatation is preserved. 7 This discordance between ACh-induced vasodilatation and flow-mediated vasodilatation can explain the low predictive power of flow-mediated vasodilatation for CE observed in the earlier study.

In the present study, endothelial function obtained using $\mathrm{ACh}$ infusion in the BA strongly correlated with that in the $\mathrm{CA}$, similar to the results of our previous report ${ }^{19}$ and these findings demonstrate that an ACh endothelial function study in the BA can substitute for one in the CA.

However, before applying the current information to the clinical setting, there are several limitations. First, in order to establish endothelial function as prognostic modality, we should compare it with conventional tests such as exercise stress testing or stress nuclear perfusion images. This information is lacking in the present study. However, the conventional modalities are less effective in patients without significant CAD. The prognostic value of endothelial function studies in low-risk populations such as those without significant CAD can be emphasized. Second, we did not perform serial endothelial function studies. The relationship between changes in the endothelial function studies and disease progression in patients with coronary risk factors and/or CAD needs to be studied in future investigations. In the present study, we did not perform serial endothelial function studies because it has not yet been established as a standard prognostic tool. Third, most of the earlier studies conducted BA endothelial function studies using ACh infusions combined with plethysmography. We need to confirm the correlation between our method with the conventional one using plethysmography. Fourth, when we measured CA and BA artery endothelial function, we injected contrast agent, which might influence the measurement of flow; however, we used this contrast agent in both the control and $\mathrm{ACh}$ infusion. As the $\mathrm{CA}$ and BA artery endothelial function studies consisted of the relative increase in flow, defined as the CA and BA blood flow indices, the effect of the contrast agent is likely to be canceled by definition. Lastly, the study population in this study was small and males predominated, so our observation should be further duplicated in future studies of a large cohort with a balanced gender ratio to confirm this result. Even when con- sidering these limitations, a less invasive modality such as a BA endothelial function study is more feasible in the routine clinical setting than an endothelial function study in the CA, which is more invasive and difficult to repeat.

In conclusion, the present study demonstrated that the $\mathrm{BA}$ vasodilator response to $\mathrm{ACh}$ is a surrogate prognostic predictor for CA endothelial function tests in patients with suspected CAD.

\section{References}

1. Casas JP, Bautista LE, Humphries SE, Hingorani AD. Endothelial nitric oxide synthase genotype and ischemic heart disease: Metaanalysis of 26 studies involving 23,028 subjects. Circulation 2004; 109: $1359-1365$.

2. Burnett JC Jr. Vasopeptidase inhibition: A new concept in blood pressure management. J Hypertens 1999; 17(Suppl): S37-S43.

3. Esen AM, Barutcu I, Acar M, Degirmencl B, Kaya D, Turkmen M, et al. Effect of smoking on endothelial function and wall thickness of brachial artery. Circ J 2004; 68: 1123-1126.

4. Kawamura A, Miura S, Murayama T, Iwata A, Zhang B, Nishikawa $\mathrm{H}$, et al. Increased expression of monocyte CD11a and intracellular adhesion molecule-1 in patients with initial atherosclerotic coronary stenosis. Circ J 2004; 68: 6-10.

5. Anderson TJ, Uehata A, Gerhard MD, Meredith IT, Knab S, Delagrange D, et al. Close relation of endothelial function in the human coronary and peripheral circulations. J Am Coll Cardiol 1995; 26: $1235-1241$.

6. Takase B, Uehata A, Akima T, Nagai T, Nishioka T, Hamabe A, et al. Endothelium-dependent flow-mediated vasodilation in coronary and brachial arteries in suspected coronary artery disease. Am J Cardiol 1998; 82: 1535 - 1539 .

7. Suwaidi JA, Hamasaki S, Higano ST, Nishimura RA, Holmes DR Jr, Lerman A. Long-term follow-up of patients with mild coronary artery disease and endothelial dysfunction. Circulation 2000; 101: 948-954.

8. Schachinger V, Britten MB, Zeiher AM. Prognostic impact of coronary vasodilator dysfunction on adverse long-term outcome of coronary heart disease. Circulation 2000; 101: 1899-1906.

9. Heitzer T, Schlinzig T, Krohn K, Meinertz T, Munzel T. Endothelial dysfunction, oxidative stress, and risk of cardiovascular events in patients with coronary artery disease. Circulation 2001; 104: 2673 2678.

10. Chan SY, Mancini GB, Kuramoto L, Schulzer M, Frohlich J, Ignaszewski A. The prognostic importance of endothelial dysfunction and carotid atheroma burden in patients with coronary artery disease. J Am Coll Cardiol 2003; 42: 1037-1043.

11. Brevetti G, Silvestro A, Schiano V, Chiariello M. Endothelial dysfunction and cardiovascular risk prediction in peripheral arterial disease: Additive value of flow-mediated dilation to ankle-brachial pressure index. Circulation 2003; 108: 2093-2098.

12. Gokce N, Keaney JF Jr, Hunter LM, Watkins MT, Menzoian JO, Vita JA. Risk stratification for postoperative cardiovascular events via noninvasive assessment of endothelial function: A prospective study. Circulation 2002; 105: 1567-1572.

13. Gokce N, Keaney JF Jr, Hunter LM, Watkins MT, Nedeljkovic ZS, Menzoian JO, et al. Predictive value of noninvasively determined endothelial dysfunction for long-term cardiovascular events in patients with peripheral vascular disease. J Am Coll Cardiol 2003; 41: $1769-1775$

14. Fathi R, Haluska B, Isbel N, Short L, Marwick TH. The relative importance of vascular structure and function in predicting cardiovascular events. J Am Coll Cardiol 2004; 43: 616-623.

15. Bugiardini R, Manfrini O, Pizzi C, Fontana F, Morgagni G. Endothelial function predicts future development of coronary artery disease: A study of women with chest pain and normal coronary angiograms. Circulation 2004; 109: 2518-2523.

16. Halcox JP, Schenke WH, Zalos G, Mincemoyer R, Prasad A, Waclawiw MA, et al. Prognostic value of coronary vascular endothelial dysfunction. Circulation 2002; 106: 653-658.

17. Perticone F, Ceravolo R, Pujia A, Ventura G, Iacopino S, Scozzafava A, et al. Prognostic significance of endothelial dysfunction in hypertensive patients. Circulation 2001; 104: 191-196.

18. Hashimoto M, Ishida Y, Sakuma I, Tanaka Y, Masumura S. Notes on the acetylcholine-induced relaxation of porcine coronary arteries. Life Sci 1994; 54: 525-531.

19. Takase B, Hamabe A, Satomura K, Akima T, Uehata A, Ohsuzu F, et al. Close relationship between the vasodilator response to acetyl- 
choline in the brachial and coronary artery in suspected coronary artery disease. Int J Cardiol 2005; 105: 58-66.

20. Tron C, Donohue TJ, Kern MJ. Normal coronary flow velocity patterns: Considerations of artifacts, arrhythmias, and anomalies. In: Kern MJ, editor. Interventional physiology rounds, 1st edn. New York: John Wiley \& Sons; 1998; 173-182.

21. Cardillo C, Kilcoyne CM, Cannon RO 3rd, Panza JA. Attenuation of cyclic nucleotide-mediated smooth muscle relaxation in blacks as a cause of racial differences in vasodilator function. Circulation 1999; 99: $90-95$.

22. Hollenberg SM, Klein LW, Parrillo JE, Scherer M, Burns D, Tamburro P, et al. Coronary endothelial dysfunction after heart transplantation predicts allograft vasculopathy and cardiac death. Circulation 2001; 104: 3091-3096.

23. Targonski PV, Bonetti PO, Pumper GM, Higano ST, Holmes DR Jr, Lerman A. Coronary endothelial dysfunction is associated with an increased risk of cerebrovascular events. Circulation 2003; 107:
2805-2809.

24. Meisel SR, Mazur A, Chetboun I, Epstein M, Canetti M, Gallimidi J, et al. Usefulness of implantable cardioverter-defibrillators in refractory variant angina pectoris complicated by ventricular fibrillation in patients with angiographically normal coronary arteries. Am J Cardiol 2002; 89: 1114-1116.

25. Kumar A, Chandna H, Santhanam V, Denes P. Refractory vasospasm with a malignant course. Clin Cardiol 2000; 23: 127-130.

26. Neunteufl T, Heher S, Katzenschlager R, Wolfl G, Kostner K, Maurer $\mathrm{G}$, et al. Late prognostic value of flow-mediated dilation in the brachial artery of patients with chest pain. Am J Cardiol 2000; 86: $207-210$.

27. Zeiher AM, Drexler H, Wollschlager H, Just H. Modulation of coronary vasomotor tone in humans: Progressive endothelial dysfunction with different early stages of coronary atherosclerosis. Circulation 1991; 83: $391-401$. 